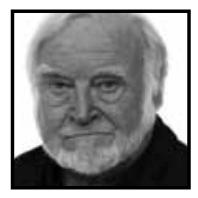

\title{
Commentary Reflections on Some Dangers to Childhood Creativity
}

\author{
Mihaly Csikszentmihalyi, Claremont Graduate University
}

\section{ABSTRACT}

In this commentary, renowned author and psychologist Mihaly Csikszentmihalyi reflects on the state of creativity in today's children. From his many years of studying creativity, Dr. Csikszentmihalyi has observed that the most creative people share a common experience in childhood: that of being left alone, often in a barren environment, and of being bored. Paradoxically, solitude and boredom become the springboard from which a creative passion is born. Finally, the author questions whether the presence of technology in children's lives today is an opportunity for learning or a source of effortless experiences that are not conducive to nurturing creativity.

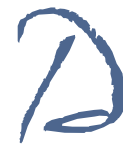

espite the fact that I am writing these notes right after Thanksgiving, which means that Christmas carols already drift in the air and lovely light-bulb decorations swing between the neighborhood's trees, in writing about creativity I feel overcome by a distinctly Grinchish feeling. It's such a lovely topic, so why is it so difficult to be upbeat about it?

Creativity has been a steady interest of mine for the past 58 years, ever since we started the first research on young artists with J.W. Getzels. Or even earlier, when I had no idea as yet that you could research such topics. But while at the beginning I was driven by a curiosity to understand how such a wonderful thing as creativity was possible, now I am more worried about understanding what we should do so as not to lose it. 
Clearly creativity, at least creativity with a capital " $C$," waxes and wanes across cultures and through time. For all we know, potentially creative children are born at the same rate in every culture and generation. But the opportunity to transform the potential into actuality does vary a great deal. Athens was a hotbed of new ideas and wonderful products two and a half millennia ago; Florence in the Fifteenth Century; Paris in the Nineteenth. Is the United States poised to be the next cauldron of creative ideas, the kind of ideas that give hope for a meaningful, worthwhile future to the rest of the world? Or will G.B. Shaw's quip to the effect that "America is the first great civilization to start declining before flourishing" come true? There are troubling signs that point towards the second alternative. Everyone knows that in terms of test scores, the US sadly underperforms most advanced countries in terms of reading, mathematics, and science. Even though such scores are no indication of creativity, they are the substance from which creativity can arise. So it is worrisome to see that despite the enormous material advantages enjoyed by the US, its children are less able to read and do mathematics than the children of Finland, Poland, or Luxembourg, not to mention China, Korea, or Singapore.

This concern took added weight as I was listening to the individuals whose interviews formed the basis of my book, Creativity. These were men and women in their sixties and older who had left their mark on the culture, contributing to the advancement of the arts and the sciences. A dozen were Nobel laureates, two of them twice over.

One of the things a few of these unimpeachably creative folks mentioned spontaneously was that creativity in children was becoming endangered. When I asked why, an unexpected answer kept cropping up: "Well, the problem" they would say, "is that children are no longer bored." At first this answer appeared to me strange and counterintuitive. But after a while, I began to see that it contained more than a grain of truth.

It turns out that many of these outstanding persons started the work that has changed the world we live in because they had to learn to find enjoyment in a barren environment. Vera Rubin, an astronomer who revolutionized our understanding of how galaxies move, remembers that when she was seven years old her family moved from the center of Chicago to the edge of the city, into an apartment building across from a vast cemetery. Without friends, in a strange new place, she felt lonely and lost. Because of the location, the nights were dark, and for the first time in her life she could experience, laying in her bed, the full impact of the starry skies. She spent more and more time just watching the slow wheeling of stars and planets over her 
head. Fortunately her father, who was an engineer, understood Vera's budding passion, and he helped make a small telescope out of an old cardboard tube and a few lenses. After she was able to see clearly the rings of Saturn and the moons of Jupiter, she said, "I could not understand why every adult would not be an astronomer." In a nutshell, Vera Rubin's experience was replicated in the majority of the creative individuals' life stories.

The commonalities included a temporary change of lifestyle or restriction of movement due to illness or isolation. In this condition the child felt lonely and bored. Then an unexpected event-often quite ordinary-opened some opportunities to the child. If the child seized the chance, and if she was fortunate to have the support of caring adults, the child began a journey out of a boring reality into the freedom of a new world. Of course, once the journey started, the child needed a great deal of good luck and support before her interest could make a difference-before the play became creativity.

Heinz Meyer-Leibnitz, a German physicist whose influential career was crowned by Nobel prizes being given to two of his students (for different discoveries started in his lab), had a touch of tuberculosis when he was still in grade school. His parents sent him to stay with a farmer's family in the Bavarian Alps. At first he laid in bed all of the time, while his hosts went on with the chores of their peasant life out in the fields and the meadows. Later he began to take short walks around the house, in the shadow of the pine forests. The inscrutable peaks of the Alps towering above the village led him to wonder about the nature of stone, and then matter in general. Slowly he was no longer alone and listless; he started reading about physics ... half a century later he became the Director of the first European nuclear research laboratory in Grenoble, France.

Oscar Peterson, the great jazz pianist, grew up in a poor district in Montreal, Canada. His father was a railway porter who left Mondays on the transcontinental run to Vancouver, and returned home for a few days a week later. His mother left to work every morning, and Oscar was left home alone with nothing to do. But listening to old LP records, he became fascinated by the sound of piano, and kept badgering his parents to get an instrument like that for him. Finally his father gave in, and bought an old decrepit piano for his son-but with one condition: that Oscar would learn to play one new song every time he took a trip away on the railroad. The condition was accepted, and from then on as soon as his father came back from Vancouver, the first thing he did upon his return was to sit down in the parlor, and ask Oscar: "well, son, let me hear that song you were supposed to learn for today." And if the performance 
was poor, he let his son know it in no uncertain terms; if the song was well played, he slapped his knees in satisfaction.

Or Ellen Lanyon, a painter who has become over the years a friend and mentor to dozens of beginning women artists. She grew up with a single mother who had to work each day. Just before starting school, Ellen came down with scarlet fever and had to stay in bed while her mother was away at her job. After the first day alone, she asked her mother if she could buy a pad of paper and some water colors for her to have something to do during the long boring day. Her mother obliged, and by the end of the day Ellen had filled the pad with paintings-of the window, the sofa, the cat in various poses... Out of paper, she asked the mother for another pad. Although the mother agreed, she forgot to buy more paper the next day. Growing increasingly bored, Ellen began to paint on her bed sheets, and then the walls of her room. When her mother returned from work, instead of bawling Ellen out as she had feared, she promised the girl to make sure to get more paper for her next day, which she then did. By then, however, Ellen had learned a life-changing lesson: nobody needs to be bored, and everyone has the means to escape that uncomfortable condition.

But why is it that not every child gets to learn this lesson? One possible reason, one that the creative people I interviewed mentioned more than any other, is that we have made it too easy for them to escape from boredom and loneliness. All they need to do is turn on a TV set, or a video game, and a stream of glittering information will capture their attention; no need to figure anything out, to use the resources of the mind, to engage reality-voilà-you are (virtually) connected with the stream of life, you are back where the action is, in the middle of things.

Of course, this diagnosis might be no more than the grumbling of an older generation looking disapprovingly at a world it no longer understands. I remember that when I was a child and started reading incessantly; my father (who was a fairly well educated man for his time and held a distinguished professional position) would become frustrated and angry: "What is wrong with you?" he would ask; "why aren't you doing something useful? How can you waste all your time reading books?" Certainly, the written word can also become a medium of cheap escape. But it has the advantage of requiring more effort on the part of the reader, an effort that leads to habits of concentration and the development of skills involved in translating abstract linguistic signs into images, events, and ideas that can be used to create alternative worlds.

In our research we have learned that children and adolescents report being more happy and motivated when they watch TV that when they read. On the other 
hand, in one study where we tried to predict which high school students would end up in good colleges, we found that two questions were the most significant predictors of whether the teenager would end up in college, and if they did, on the quality of the college they were admitted to. The two questions were: "do you have a TV set in your bedroom?" and, "are there more than 50 books in your home?" If the answer was "yes" to the first, and "no" to the second question, the chances that the teen would end up in college were slim, and the chances of ending up in an academically demanding college next to nil. And this controlling for parental income and education.

No one, I hope, will take these findings literally and conclude that if they remove the TV from the child's room and buy 50 books at random from the nearest bookstore their offspring will be offered a scholarship at Harvard. These questions were simply diagnostic of a home environment that was either friendly or hostile to a child's developing interests and mental discipline. And that environment includes, above everything else, a parental commitment to a lifestyle conducive to learning. Some of the parents of the creative people we studied had developed a network of relatives or friends who were interested in one topic or another, and then prevailed on them to become mentors to their children; uncle Rob introduced one child to bird watching and the attendant avian lore; cousin Rita took the other child, who loved dancing, to every ballet performance in the vicinity. Another creative person, who grew up in poor circumstances in the Northeast, remembers that the entire family would pile into their old car on weekends and drive to some free museum, historical site, or architectural site within driving distance; by the time she was a teenager, she felt connected to her environment by strong strands of meaningful memories.

It is also true that for a few children, the readily available technology offers tremendous opportunities for learning and creating new programs, new games, new apps, even new hardware. But how many are doing this? For the great majority, alas, the new media are a limitless market of consumption, a source of effortless experience. And once a child enters the network of electronic communication, it becomes difficult to step back from it. The cell phone and the Internet allow each child to be connected. Unfortunately, creativity requires periods of solitude. Without prolonged periods of concentration, which requires solitary "work," only the most superficial creativity is possible.

Not that the creative person must always work alone. To the contrary, collaboration with peers who share the person's interest is just as important for creativity as solitude is. The problem is that solitude has become more and more difficult to find. In another study, this with talented teenagers, we found that high school students 
who had outstanding talent in mathematics, science, visual arts, music, and athletics spent more time alone than typical teenagers. And more importantly, they tended to feel less lonely when they were alone. Those talented teens who disliked being alone avoided solitude, and if they could not hang out with their friends they would be on the phone (this was before they could twitter, as the technology was not yet advanced enough...) By the time they were finishing high school, the teens who had trouble staying alone had reverted to being average students; those who could stand solitude continued to develop their talents. Of course, adolescents have always been gregarious, and solitude has been generally considered a fate only marginally better than death. To avoid feeling alone, children in the past had to learn how to make friends, how to relate to other people's world-views, and above all else-how to make the best of solitude itself, when there is no other choice. And those are usually the times when creativity flourishes best.

Obviously, it is not the technology itself that is to blame, but the use we make of it. The evolution of humanity has always involved a step forward in the use of tools, from stone axes to spaceships. In each case, the technology allowed us to do something faster, easier, more efficiently. At the same time, the introduction of new tools has also often resulted in unexpected consequences that were less desirable. This was not much of a problem as long as the technology was local and could do little damage. But when a medium can reach every child, and is so seductive that it captures a great deal of their free attention, then we better watch out.

Unfortunately, past efforts to control the media have been both ineffectual and reactionary. The Popes tried for centuries to prevent books to carry information that they considered dangerous to the readers' souls. The Nazi storm troopers burned books that undermined their ideology, and so did Mao Tse-tung's Red Guards-all to no avail. We clearly need more creative solutions for how to prevent new technologies from sapping the imagination of children.

And this leads us to another issue that we might want to consider: how can we expect children to be creative when we don't teach them how? Our entire educational system is geared to produce convergent thinkers, solvers of problems that are presented to them and for which tried-and-true solutions exist. Unfortunately, a great many of the problems that life will present them are ill defined, and cannot be solved by applying known methods. To use a simple parallel, we aspire to teach our children to be good chess players - but life is more like a poker game. If we wish children to be creative, we need to become more creative ourselves. 
These are some of the Grinchean thoughts that the Holiday Season suggests. But there is one more. Fifty years ago, creativity was a minor concern of parents and educators. Each year, however, it appears that more and more concern is expressed about how to make our children more creative. This is a good trend, I think, up to a point. But it can be overdone: pursuing creativity at the expense of solid knowledge will lead nowhere. In fact, "creativity" does not exist in the abstract. You can be a creative physicist, in which case you are unlikely to be also a creative poet, or pastry chef, or plumber. And a creative poet is unlikely to do creative work as a physicist. So the first thing children need is to discover a passion, or at least an interest in a particular aspect of the world. And then they need the help of parents and teachers to develop their interest in creative ways-by understanding the context, the causes, and the consequences of the knowledge they are acquiring. They may not become Mozarts or Einsteins in the process, but their lives are likely to become meaningful and productive.

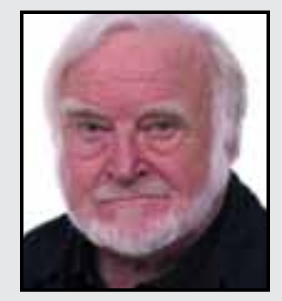

Mihaly Csikszentmihalyi is the C.S. and D.J. Davidson Professor of Psychology at the School of Behavioral and Organizational Sciences, and the Peter F. Drucker Graduate School of Management, at Claremont Graduate University; and coDirector of the Quality of Life Research Center. He is a Fellow of several scientific societies, The National Academy of Education, and a member of the Hungarian Academy of Sciences. In addition to the hugely influential Flow: The Psychology of Optimal Experience, he is the author of thirteen other books translated into 23 different languages, and some 245 research articles on optimal development, creativity, and well-being. 